\title{
Chronic $\beta$-Adrenergic Receptor Stimulation Enhances the Expression of G-Protein Coupled Receptor Kinases, GRK2 and GRK5, in Both the Heart and Peripheral Lymphocytes
}

\author{
Naotsugu Oyama, MD; Kazushi Urasawa, MD; Satoshi Kaneta, MD; Hidetsugu Sakai, MD; \\ Takahiko Saito, MD; Chika Takagi, MD; Ichiro Yoshida, MD; \\ Akira Kitabatake, MD; Hiroyuki Tsutsui, MD
}

\begin{abstract}
Background Enhanced expression of G protein-coupled receptor kinase (GRK) has been reported in failing hearts and in the present study the stability of enhanced GRK mRNA expression, and the correlation between the expression level of GRK mRNA in peripheral lymphocytes and in the heart were both evaluated.

Methods and Results Isoproterenol was injected into rats for 2 weeks, and then GRK5 mRNA was assessed by quantitative reverse transcriptase-palymerase chain reaction. An enhanced expression of cardiac GRK5 mRNA was observed even after 4 weeks of recovery. The isoproterenol-induced increased expression of GRK2 and GRK5 mRNA was equally observed in the heart and lymphocytes, and there was a close correlation between the heart and lymphocytes in the level of expression of each GRK mRNA.

Conclusions The GRK mRNA level is maintained at a high level for a long period without continuous $\beta$-adrenergic receptor stimulation. The level in circulating lymphocytes could be used as a surrogate marker to estimate the level of cardiac GRK expression and, presumably, the $\beta$-adrenergic receptor function of cardiomyocytes. (Circ J 2005; 69: 987-990)
\end{abstract}

Key Words: Catecholamine; G protein-coupled receptor kinase; Receptor down-regulation

C ongestive heart failure (CHF) is one of the leading causes of death in Japan, with several distinct preceding cardiovascular diseases such as primary myocardial disease, ischemic heart disease and valvular heart disease. Recently, Shiba et al reported that the 3-year all-cause mortality rate of stable Japanese CHF patients is as high as $21 \%$ !

Various neurotransmitters, hormones, and growth factors are reported to be increased in patients with CHF, and enhanced sympathetic nerve activity, in particular, is closely associated with CHF. Norepinephrine released from the sympathetic nerve endings is recognized by cell surface $\beta$-adrenergic receptors $\beta \mathrm{AR}$ ) and agonist binding to the $\beta$ AR activates several down-stream molecular events, including activation of stimulatory GTP binding proteins, adenylyl cyclace (AC) and protein kinase A, which result in positive inotropism and chronotropism? However, continuous exposure to agonists causes a well-known phenomenon, "desensitization" of the $\beta$ AR. Sustained adrenergic stimulation leads to various alterations in the $\beta$ AR signaling, including phosphorylation of $\beta$ AR (uncoupling), a decrease in the number of $\beta$ AR (down-regulation), 4 reduced AC activity 5,6 and an increase in inhibitory GTP binding

(Received February 8, 2005; revised manuscript received May 12, 2005; accepted May 17, 2005)

Department of Cardiovascular Medicine, Hokkaido University Graduate School of Medicine, Sapporo, Japan

Mailing address: Kazushi Urasawa, MD, PhD, Department of Cardiovascular Medicine, Hokkaido University Graduate School of Medicine, Kita 15, Nishi 7, Kita-ku, Sapporo 060-8638, Japan. E-mail: kazurasa@med.hokudai.ac.jp protein? In general, the function of G-protein coupled receptors is regulated through their phosphorylation by a group of serine-threonine protein kinases known as G protein-coupled receptor kinases (GRK). So far, 6 different GRK isoforms have been cloned 8,9 and of them, GRK2 (also known as $\beta$ AR kinase 1, $\beta$ ARK1), and GRK5 are abundantly expressed in the mammalian heart ${ }^{10}$ GRKmediated phosphorylation of $\beta$ AR plays a pivotal role in maintaining intracellular homeostasis against overwhelming $\beta$ AR stimulation!11 Enhanced protein expression and activity of GRK2 have been reported in the hearts of CHF patients ${ }^{12}$ and in an animal model of $\mathrm{CHF}^{13}$ and similar results have been reported for GRK5 expression!4 These findings suggest that the enhanced expression of GRK2 and GRK5 might cause a deterioration of the signaling efficiency of the cardiac $\beta \mathrm{AR}-\mathrm{AC}$ system in the failing heart. Based on this evidence, we speculated that the level of expression of GRK2/GRK5 might be a useful molecular marker of the severity of CHF and the phosphorylation status of cardiac $\beta$ AR. In this context, we aimed to clarify 2 issues: (1) the durability of the overexpressed GRK mRNA after termination of $\beta$ AR stimulation, and (2) the ability to estimate the cardiac GRK level using peripheral blood cells.

\section{Methods}

Thermus Acquaticus

Taq DNA polymerase, deoxynucleotides used for the polymerase chain reaction (PCR), Molony Murine Leukemia Virus (MMLV) for reverse transcriptase (RT), 
Table 1 Effect of Catecholamine Injection on GRK2 and GRK5 mRNA Expression in Rat Hearts and Lymphocyt

\begin{tabular}{lccccc}
\hline \hline \multirow{2}{*}{ Group } & \multicolumn{2}{c}{ GRK2 $m$ mRNA (AU) } & & \multicolumn{2}{c}{ GRK5 mRNA (AU) } \\
\cline { 2 - 3 } \cline { 5 - 6 } & Heart & Lymphocyte & & Heart & Lymphocyte \\
\hline \multirow{2}{*}{ CNT } & $1.98 \pm 0.19$ & $1.05 \pm 0.11$ & & $1.16 \pm 0.22$ & $0.90 \pm 0.08$ \\
ISO & $2.94 \pm 0.34^{*}$ & $1.92 \pm 0.20^{* *}$ & & $1.51 \pm 0.23^{*}$ & $1.27 \pm 0.12^{\dagger}$ \\
\hline
\end{tabular}

GRK, G protein-coupled receptor kinase; AU, arbitrary unit; CNT, control group; ISO, isoproterenol group. * $p<0.001, * * p<0.005$, t $p<0.01$ vs control group.
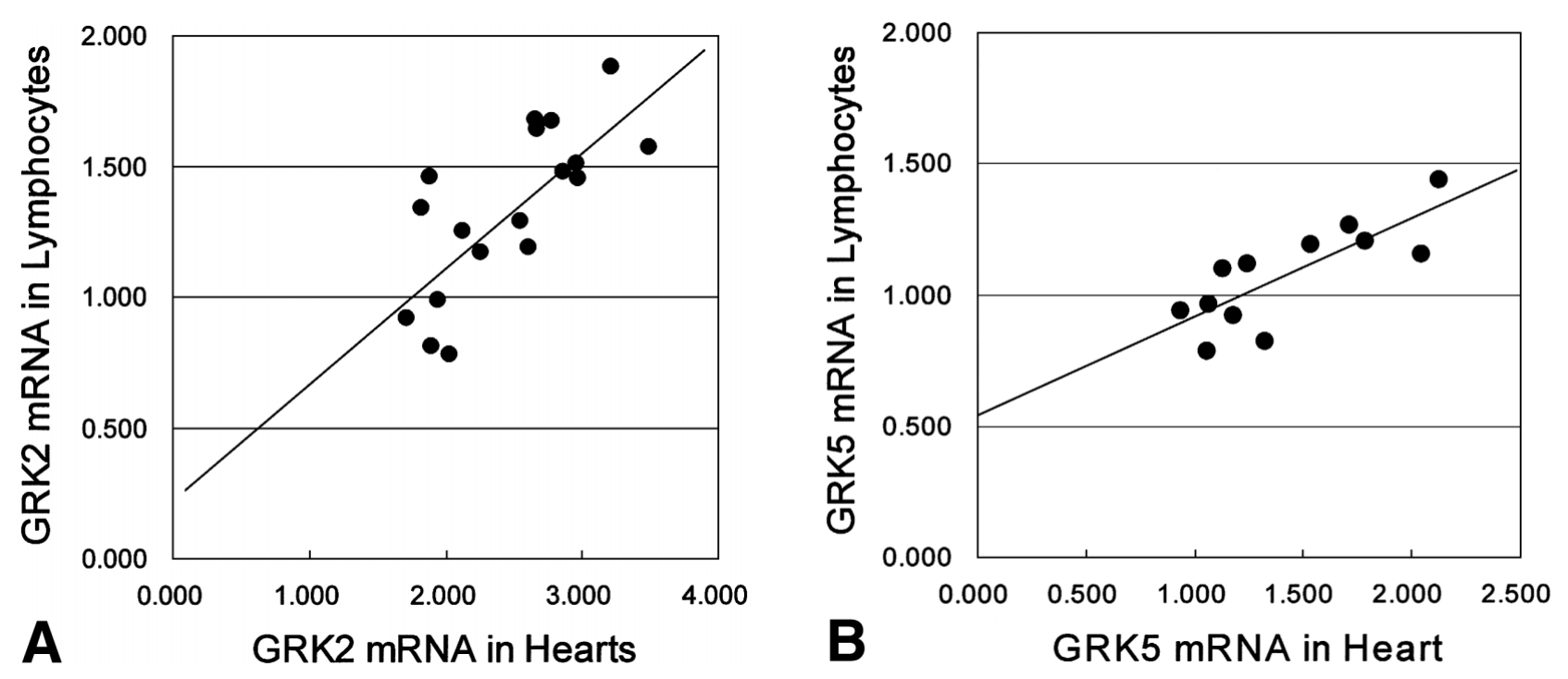

Fig 1. Correlation of G protein-coupled receptor kinase (GRK) mRNA expression in the heart and lymphocytes. (A) GRK2 mRNA, (B) GRK5 mRNA. Unit, arbitrary unit.

and restriction endonucleases and other modifying enzymes were purchased from Life Technologies (Tokyo, Japan). All other chemical reagents were purchased from Sigma (St Louis, MO, USA).

\section{Animal Model}

Twelve-week-old male Wistar rats were obtained from Hokudo (Sapporo, Japan) and for 2 weeks isoproterenol $\left(1 \mu \mathrm{g} \cdot \mathrm{kg}^{-1} \cdot \mathrm{min}^{-1}\right)$ was injected subcutaneously using implanted osmotic mini-pumps. Saline-infused rats were used for controls. To test the stability of GRK mRNA, rats were given isoproterenol $\left(25 \mathrm{mg} \cdot \mathrm{kg}^{-1} \cdot \mathrm{day}^{-1}\right)$ via intraperitoneal injection for 2 weeks to induce cardiac hypertrophy. The dose of isoproterenol was empirically determined so as to obtain maximal enhancement of GRK mRNA expression within an acceptable acute mortality of the animal model. Control Wistar rats were given the same amount of vehicle. Cardiac GRK mRNA expression was assessed by quantitative RT-PCR at 2 weeks (just after the cessation of isoproterenol injection), 4 weeks (after 2 weeks of recovery), 6 weeks (after 4 weeks of recovery) and 10 weeks (after 8 weeks of recovery).

Extraction of Total RNA From Rat Hearts and Lymphocytes

Total RNA was extracted from rat ventricles using the single-step method ${ }^{15}$ and the final RNA pellets were suspended in an appropriate volume of diethylpyrocarbonatetreated water to obtain an RNA concentration of 1-2 $\mu \mathrm{g} \mu \mathrm{l}$. The lymphocyte fraction was separated from whole blood through Ficall-Paque gradient centrifugation ${ }^{16,17}$ and total RNA was extracted from the lymphocyte fraction using the single-step method.

\section{Quantitative Measurement of GRK2 and GRK5 mRNA by} $R T-P C R$

One microgram of total RNA was incubated with 200 units of MMLV-RT and $23 \mu \mathrm{mol} / \mathrm{L}$ random hexamers at $37^{\circ} \mathrm{C}$ for $30 \mathrm{~min}$ to produce cDNA. The reaction was stopped by heating samples for $5 \mathrm{~min}$ at $70^{\circ} \mathrm{C}$. The following primers were used to amplify GRK2 and GRK5 partial cDNA: GRK2 sense 5'-GACTGGTTCTCCCTGGGCTG3' (position 1,116-1,135), GRK2 antisense 5'-CCATGCA TGATGCAGTCCTT-3' (position 1,667-1,686), and GRK5 sense 5'-GGCCGT AAGGAGAAGGTGAA-3' (position 1,359-1,378), GRK5 antisense 5'-CTAGCTGCTTCC GG TGGAGTT-3' (position 1,735-1,773), respectively. For GRK2, the reaction was performed with 30 s of denaturation at $94^{\circ} \mathrm{C}$, annealing for $30 \mathrm{~s}$ at $53^{\circ} \mathrm{C}$ and $30 \mathrm{~s}$ of extension at $72^{\circ} \mathrm{C}$ for 28 cycles. For GRK5, the reaction was performed with $30 \mathrm{~s}$ of denaturation at $95^{\circ} \mathrm{C}, 30 \mathrm{~s}$ of annealing at $55^{\circ} \mathrm{C}$, and $30 \mathrm{~s}$ of extension at $72^{\circ} \mathrm{C}$ for 29 cycles. These conditions were determined by preparatory experiments in order to obtain linearity on the amount of PCR product up to 31 cycles (data not shown). PCR products were separated through $1 \%$ agarose gel electrophoresis, then stained by $0.5 \mu \mathrm{g} / \mathrm{ml}$ ethidium bromide and photographed on a UV transilluminator. The intensities of the DNA bands were assessed by densitometric scanning of the photographs and were used to calculate the relative level of GRK mRNA expression (arbitrary unit (AU)) to that of a control sample using image analyzing software, NIH image.

\section{Data Analysis}

Data are expressed as means \pm SD. Values were com- 
Table 2 Basic Characteristics of the Control and Isoproterenol-Infused Rats

\begin{tabular}{lcccc}
\hline \hline & $C N T$ & $I S O$ & $C N T 2 W$ & $I S O 2 W$ \\
\hline$B W(\mathrm{~g})$ & $376.0 \pm 4.3$ & $356.0 \pm 10.4$ & $400 \pm 6.0$ & $397.5 \pm 16.3$ \\
$P R($ beats/min $)$ & $334.9 \pm 12.2$ & $320.7 \pm 14.0$ & $355.6 \pm 8.6$ & $308.0 \pm 26.8$ \\
$s B P(\mathrm{mmHg})$ & $142.7 \pm 3.3$ & $141.3 \pm 13.9$ & $146.6 \pm 6.4$ & $139.1 \pm 10.3$ \\
$d B P(\mathrm{mmHg})$ & $98.6 \pm 7.3$ & $86.5 \pm 6.2$ & $91.2 \pm 13.8$ & $100.3 \pm 10.8$ \\
$H W / B W$ & $0.147 \pm 0.006$ & $0.242 \pm 0.015^{*}$ & $0.154 \pm 0.004$ & $0.155 \pm 0.014$ \\
\hline
\end{tabular}

CNT, control group; ISO, isoproterenol group; BW, body weight; PR, pulse rate; sBP, systolic blood pressure; dBP, diastolic blood pressure; HW, heart weight. * $p<0.0005$ vs control.

pared using unpaired t-test, and accepted as statistically significant when the p-value was less than 0.05 .

\section{Results}

Effect of Chronic Isoproterenol Infusion on GRK mRNA

Expression of the Heart and Lymphocytes

Continuous subcutaneous injection of isoproterenol for 2 weeks induced cardiac hypertrophy in rats. The heart to body weight ratios of the isoproterenol-infused rats were significantly higher than those of controls $(\mathrm{p}<0.0001$, data not shown). We examined the expression level of GRK2 mRNA and GRK5 mRNA of the hearts and lymphocytes in both groups by means of quantitative RT-PCR. Enhanced expression of GRK2 and GRK5 mRNA was observed in both the hearts $(\mathrm{p}<0.001)$ and lymphocytes (GRK2: $\mathrm{p}<0.05$, GRK5: $\mathrm{p}<0.01$ ) of the isoproterenol infused rats (Table 1). There was a significant correlation between the hearts and lymphocytes in the level of GRK mRNA expression (GRK2: $\mathrm{r}=0.74, \mathrm{p}<0.001, \mathrm{n}=18$ (Fig 1A); GRK5: $\mathrm{r}=0.79$, $\mathrm{p}<0.005, \mathrm{n}=12$ (Fig 1B)).

\section{Effect of Isoproterenol and Stability of GRK $m R N A$}

In order to investigate the longevity of the overexpressed GRK mRNA, isoproterenol $(25 \mathrm{mg} / \mathrm{kg})$ was subcutaneously injected once daily for 2 weeks. The basic characteristics of the control and isoproterenol-infused rats are shown in Table 2 (6 animals in each group). Body weight, pulse rate, systolic blood pressure and diastolic blood pressure were similar between the 2 groups. The heart weight-body weight ratio just after the termination of isoproterenol was significantly higher in the isoproterenol-infused rat group $(\mathrm{p}<0.0005)$, as reported previously? The ratio, however, was not significantly different between the 2 groups at 2 weeks after the termination of isoproterenol injection. Because chronic injection of isoproterenol enhanced GRK5 mRNA more markedly than GRK2 mRNA, the following experiment was conducted. The expression level of GRK5 mRNA was assessed by quantitative RT-PCR just after cessation of isoproterenol infusion and at 2, 4 and 8 weeks later. As shown in Fig 2, quantitative RT-PCR revealed that the expression of GRK5 mRNA was significantly higher in the hearts of isoproterenol-infused rats than in those of controls $(1.74 \pm 0.89$ and $3.58 \pm 1.29$ AU for control and isoproterenol-infused group, respectively; $\mathrm{p}<0.01)$. Enhanced expression of GRK5 mRNA was observed up to 4 weeks into the recovery period $(2.00 \pm 0.21$ and $3.44 \pm 0.67 \mathrm{AU}$ for control and isoproterenol infused group after 2 weeks respectively; $\mathrm{p}<0.01 ; 1.56 \pm 0.32$ and $2.61 \pm 0.27$ AU for control and isoproterenol-infused group respectively; $\mathrm{p}<0.01$ ). Eight weeks after the cessation of isoproterenol, the GRK5 mRNA expression level of the treated rats had returned to the control level $(1.25 \pm 0.31$ and $1.43 \pm 0.27 \mathrm{AU}$ for control and isoproterenol-infused group respectively; NS).

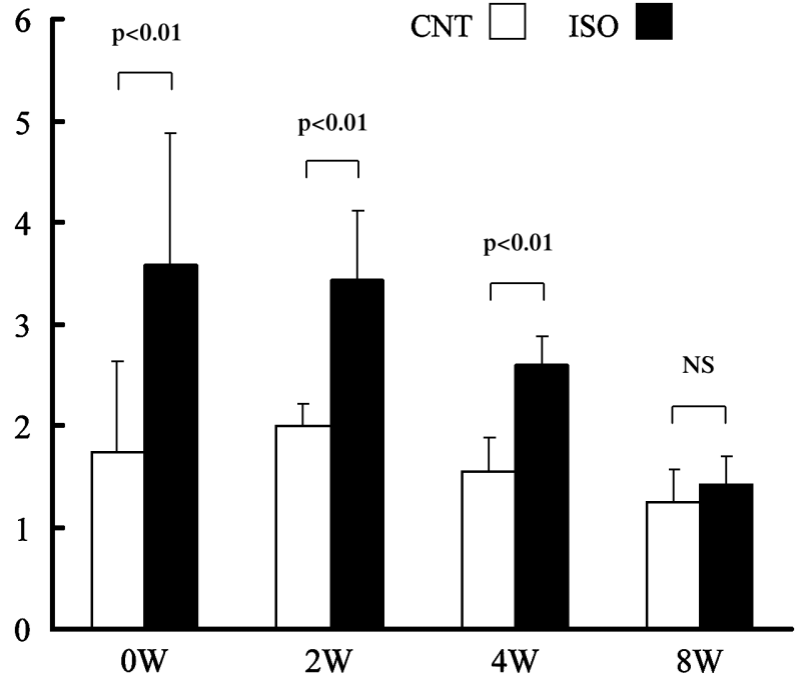

Fig 2. GRK5 mRNA expression in rat hearts after 2 weeks of isoproterenol treatment. CNT, control group; ISO, isoproterenol group; $2 \mathrm{~W}, 2$-week recovery period; $4 \mathrm{~W}, 4$-week recovery period; $8 \mathrm{~W}, 8$ week recovery period; Unit, arbitrary unit.

\section{Discussion}

It is well known that chronic infusion of norepinephrine or isoproterenol induces cardiac hypertrophy accompanied by fibrotic changes in the cardiac interstitial tissue ${ }^{18-20}$ Sustained stimulation of the $\beta$ AR was reported to increase the expression of GRK2, whereas chronic administration of $\beta$-blocker decreased it. ${ }^{21}$ Because the promoter sequence of the GRK2 gene contains multiple AP2 sites,2 it is reasonable to speculate that $\beta$ AR stimulation and the subsequent increase of intracellular PKA activity accelerates the transcriptional activity of GRK2. The effect of chronic $\beta$ AR stimulation on GRK5 expression is still controversial. In our experiments, 2 weeks of isoproterenol infusion increased not only the expression of GRK2 mRNA, but also that of GRK5, and both are known to phosphorylate $\beta$ AR in vivo? 23 Dzimiri et al also reported enhanced expression of GRK5 in the left ventricles of patients with dilated cardiomyopathy ${ }^{24}$ On the other hand, Iaccarino et al reported that $\beta$ AR stimulation did not alter the expression level of GRK5? The structure of GRK5, including its promoter sequence, should be thoroughly investigated to provide some insight to this confusion.

We confirmed that chronic isoproterenol infusion induced marked cardiac hypertrophy, as reported previously, which completely recovered within 2 weeks of cessation of the isoproterenol infusion. Interestingly, the enhanced expression of GRK5 mRNA, however, persisted well beyond the period of recovery from cardiac hypertrophy, in which the neurohumoral environment had already returned to 
normal. Either sustained transcriptional activity of GRK5 or prolonged half-life of GRK5 mRNA might explain this phenomenon. In any case, this characteristic temporal profile of GRK5 mRNA expression might enable evaluation of the severity of CHF after successful treatment of the hemodynamic instability of such patients.

From a practical point of view, cardiomyocytes are somewhat hard to handle as a clinical specimen. In this study, the levels of expression of GRK2 and GRK5 were closely correlated between the heart and peripheral lymphocytes, which suggests that an elevated plasma catecholamine concentration might equally enhance the transcriptional activity of the GRK genes in 2 distinct tissues. These findings also indicated that GRK mRNA in peripheral lymphocytes could be used as a surrogate marker of cardiac GRK expression and, presumably, the level of $\beta$ AR phosphorylation in the failing heart.

\section{Study Limitations}

We used a fixed amount of cDNA from a control animal as an internal standard for the quantitative RT-PCR to compare the GRK2/5 mRNA expression level in each animal. In order to eliminate the secondary effect of chronic isoproterenol infusion on the tissue composition of the heart and the quantitative measurement of GRK2/5 mRNA, it might be better to use a housekeeping gene, such as GAPDH, as an internal standard. Recently, Mori et al reported the combined effect of celiprolol and candesartan on isoproterenol-induced heart failure. They showed that chronic isoproterenol infusion resulted in hypertrophied cardiomyocytes, disarray of myofibers and increased interstitial fibrosis, but minimal lymphocyte invasion 25 Thus, we assumed that the effect of isoproterenol-induced inflammation would be minimal in our experimental conditions.

\section{Conclusion}

We showed that GRK mRNA expression continued at a high level even after termination of $\beta$ AR stimulation, and that the GRK level in peripheral lymphocytes correlated well with that in the heart. Taking these findings together, the lymphocytic GRK level could be a more suitable clinical marker of the sympathetic drive to the failing heart during the clinical course and treatment of $\mathrm{CHF}$ patients than the conventional markers such as plasma catecholamines, atrial natriuretic peptide and brain natriuretic peptide. Verification of the evidence obtained from this study in various clinical settings might be necessary to establish the usefulness of GRK mRNA measurement for the assessment of the adrenergic receptor function of the heart.

\section{Acknowledgment}

This research was supported in part by a Research Grant from the Ministry of Health and Welfare of Japan, Grants-in Aid for Scientific Research from the Ministry of Education, Science and Culture of Japan (06454283, 06557041).

\section{References}

1. Shiba N, Watanabe J, Shinozaki T, Koseki Y, Sakuma M, Kagaya Y, et al. Analysis of chronic heart failure registry in the tohoku district: Third year follow-up. Circ J 2004; 68: 427-434.

2. Hepler JR, Gilman AG. G proteins. Trends Biochem Sci 1992; 17: 383-387.

3. Benovic JL, Strasser RH, Caron MG, Lefkowitz RJ. Beta-adrenergic receptor kinase: Identification of a novel protein kinase that phosphorylates the agonist-occupied form of the receptor. Proc Natl Acad Sci USA 1986; 83: 2797-2801.

4. Bouvier M, Collins S, O’Dowd BF, Campbell PT, Blasi AD, Kobilka $\mathrm{BK}$, et al. Two distinct pathways for cAMP-mediated down-regulation of the beta 2-adrenergic receptor: Phosphorylation of the receptor and regulation of its mRNA level. J Biol Chem 1989; 264: 1678616792.

5. Harding SE, Jones SM, O'Gara P, Vescovo G, Poole-Wilson PA. Reduced beta-agonist sensitivity in single atrial cells from failing human hearts. Am J Physiol 1990; 259: H1009-H1014.

6. Nishizawa T, Iwase M, Kanazawa H, Ichihara S, Ichihara G, Nagata $\mathrm{K}$, et al. Serial alterations of $\beta$-adrenergic signaling in dilated cardiomyopathic hamsters: Possible role of myocardial oxidative stress. Circ J 2004; 68: 1051-1060.

7. Urasawa K, Sato K, Igarashi Y, Kawaguchi H, Yasuda H. A mechanism of catecholamine tolerance in congestive heart failure: Alterations in the hormone sensitive adenylyl cyclase system of the heart. Jpn Circ J 1992; 56: 456-461.

8. Chuang TT, Iacovelli L, Sallese M, De Blasi A. G protein-coupled receptors: Heterologous regulation of homologous desensitization and its implications. Trends Pharmacol Sci 1996; 17: 416-421.

9. Haga T, Haga K, Kameyama K. G protein-coupled receptor kinases. J Neurochem 1994; 63: 400-412.

10. Lohse MJ, Benovic JL, Codina J, Caron MG, Lefkowitz RJ. Betaarrestin: A protein that regulates beta-adrenergic receptor function. Science 1990; 248: 1547-1550.

11. Hausdorff WP, Caron MG, Lefkowitz RJ. Turning off the signal: Desensitization of $\beta$-adrenergic receptor function. FASEB J 1990; 4: 2881-2889.

12. Ungerer M, Bohm M, Elce JS, Erdmann E, Lohse MJ. Altered expression of beta-adrenergic receptor kinase and beta 1-adrenergic receptors in the failing human heart. Circulation 1993; 87: 454-463.

13. Urasawa K, Yoshida I, Takagi C, Onozuka H, Mikami T, Kawaguchi $\mathrm{H}$, et al. Enhanced expression of beta-adrenergic receptor kinase 1 in the hearts of cardiomyopathic Syrian hamsters, BIO53.58. Biochem Biophys Res Commun 1996; 219: 26-30.

14. Takagi C, Urasawa K, Yoshida I, Kaneta S, Nakano N, Onozuka H, et al. Enhanced GRK5 expression in the hearts of cardiomyopathic hamsters, J2N-k. Biochem Biophys Res Commun 1999; 262: 206210.

15. Chomczynski P, Sacci N. Single-step method of RNA isolation by acid guanidinium thiocyanate-phenol-chloroform extraction. Anal Biochem 1987; 162: 156-159.

16. Lombardi MS, Kavelaars A, Schedlowski M, Bijlsma JW, Okihara KL, Van de Pol M, et al. Decreased expression and activity of G-protein-coupled receptor kinases in peripheral blood mononuclear cells of patients with rheumatoid arthritis. FASEB J 1999; 13: 715-725.

17. Boyum A. Isolation of leukocytes from human blood: A two-phase system for removal of red cells with methylcellulose as erythrocyteaggregating agent. Scand J Clin Lab Invest 1968; 97(Suppl): 9-29.

18. Boluyt MO, Long X, Eschenhagen T, Mende U, Schmitz W, Crow MT, et al. Isoproterenol infusion induces alterations in expression of hypertrophy-associated genes in rat heart. Am J Physiol (Heart Circ Physiol) 1995; 269: H638-H647.

19. Stanton HC, Brenner G, Mayfield ED Jr. Studies on isoproterenolinduced cardiomegaly in rats. Am Heart J 1969; 77: 72-80.

20. Zierhut W, Zimmer HG. Significance of myocardial alpha- and betaadrenoceptors in catecholamine-induced cardiac hypertrophy. Circ Res 1989; 65: 1417-1425.

21. Iaccarino G, Tomhave ED, Lefkowitz RJ, Koch WJ. Reciprocal in vivo regulation of myocardial $G$ protein-coupled receptor kinase expression by $\beta$-adrenergic receptor stimulation and blockade. Circulation 1998; 98: $1783-1789$.

22. Penn RB, Benovic JL. Structure of the human gene encoding the $\beta$ adrenergic receptor kinase. J Biol Chem 1994; 269: 14924-14930.

23. Freedman NJ, Liggett SB, Drachman DE, Pei G, Caron MG, Lefkowitz RJ. Phosphorylation and desensitization of the human $\beta_{1-}$ adrenergic receptor: Involvement of $\mathrm{G}$ protein-coupled receptor kinases and cAMP-dependent protein kinase. J Biol Chem 1995; 270: 17953 - 17961 .

24. Dzimiri N, Muiya P, Andres E, Al-Halees Z. Differential functional expression of human myocardial $G$ protein receptor kinases in left ventricular cardiac diseases. Eur J Pharmacol 2004; 489: 167-177.

25. Mori T, Hayashi T, Sohmiya K, Okuda N, Shimomura H, Ohkita M, et al. Mechanisms of combined treatment with celiprolol and candesartan for ventricular remodeling in experimental heart failure. Circ $J$ 2005; 69: 596-602. 